\title{
Among the risk factors of myocardial infarction, anthropometry has no association: A case control study in the central region of Sri Lanka
} \author{
Rohini Tennakoon ${ }^{3}$, Nirmali Gunawardana ${ }^{3}$, Usha Perera ${ }^{4}$, Srinath Illeperuma ${ }^{1}$ \\ ${ }^{1}$ Department of Community Medicine, University of Peradeniya, Kandy, Sri Lanka \\ ${ }^{2}$ Department of Medicine, University of Peradeniya, Kandy, Sri Lanka \\ ${ }^{3}$ General Hospital, Kandy, Sri Lanka \\ ${ }^{4}$ Ministry of Health, Colombo, Sri Lanka \\ Email: matugama@gmail.com
}

Pallegoda Vithanage Ranhith Kumarasiri ${ }^{1}$, Senanayake Abesinghe Mudiyanselage Kularatne ${ }^{2}$,

Received 9 May 2013; revised 28 May 2013; accepted 10 June 2013

Copyright (C) 2013 Pallegoda Vithanage Ranhith Kumarasiri et al. This is an open access article distributed under the Creative Commons Attribution License, which permits unrestricted use, distribution, and reproduction in any medium, provided the original work is properly cited.

\begin{abstract}
Background: In the face of rising incidence of cardiovascular disease in the globe, the associated risk factors could be country or area specific. This study aimed to identify the important risk factors of myocardial infarction (MI) prevailing in the Kandy district of Sri Lanka. Methods: In a case control design, the cases were recruited from the Coronary Care Unit, General Hospital Kandy, with the diagnosis of myocardial infarction. Matched controls were selected from the Out Patient Department with other ailments, unrelated to cardiovascular diseases. Results: There were 205 cases and 197 controls with the mean age of 56 years ( $S D \pm 8.4$ years) and 54 years ( $\mathrm{SD} \pm 9.8$ years) respectively with male: female ratio of 1:0.2. In analysis, hypertension $(\mathrm{OR}=5.09, \mathrm{CI}=$ 2.64 - 9.83), type 11 diabetes $(O R=3.45, C I=1.90$ 6.10), smoking $(O R=1.95, C I=1.44-2.65)$ and high LDL cholesterol levels $(O R=1.06, C I=1.04-1.06)$ were identified as the independent risk factors of myocardial infarction. However, the anthropometric measurements, waist hip ratio $(\mathrm{OR}=0.64, \mathrm{CI}=0.33$ 1.34) and body mass index $\geq 25(\mathrm{OR}=0.75, \mathrm{CI}=0.46$ - 1.22) did not show an association with myocardial infarctions. Conclusions: Anthropometric measurements did not qualify as risk factors of myocardial infarction in the local setting even though hypertension, diabetes, smoking and high LDL levels showed a significant association in par with the established data.
\end{abstract}

Keywords: Myocardial Infarction; Anthropometry; Risk
Factors; Case Control Study; Sri Lanka

\section{INTRODUCTION}

The worldwide incidence of cardiovascular diseases has been increasing over the years and it has become the leading cause of death universally [1]. Physical inactivity and rapid socioeconomic changes would have contributed to this trend [1]. The risk factors of cardiovascular diseases have been identified from different regions but some of these risk factors cannot be generalized without a global survey and it has been observed that these risk factors are country or area specific. The estimates show that more than $80 \%$ of the cardiovascular diseases occur in the low and middle income countries, probably due to the rapid urbanization [1]. Well recognized risk factors of ischemic heart disease (IHD), such as smoking, hypertension, diabetes and high body mass index (BMI), they are the common risk factors identified in the South Asian region [2]. It has also been revealed that people of South Asian origin living in Canada have clear difference in their risk factor profile compared to the non-South Asian Canadians [3]. In 2009, the INTERHEART China study revealed that diabetes and psychological factors were the important risk factors of MI [4]. A study done in Kuwait revealed that the age of onset of myocardial infarction (MI) in South Asian immigrants was low when compared with the native population, even though they have similar biochemical profiles [5]. These facts emphasize the importance of identifying risk factors at a country level. Once the country-specific risk factors are identified, it will facilitate the health officials to focus their preventive 
activities and to carry out the preventive programmes effectively and efficiently. In 2005, a study done in Sri Lanka showed that the prevalence of the selected cardiovascular risk factors are common in the adult Sri Lankan population and highlighted the existence of regional differences in the prevalence of these risk factors. It was further said that the prevalence of high level of risk factors requires urgent public health action [6]. However, this study was a cross-sectional study and lacked in-depth details of these risk factors. Therefore, revisiting cardiovascular risk factor assessment based on regional basis in Sri Lanka seems prudent. Hence, this study was designed as a hospital based case control study to identify the important risk factors of myocardial infarction (MI) prevailing in the Kandy district of Sri Lanka. The objectives of the study were to evaluate the association between myocardial infarction and selected anthropometric measurements, behavioral factors, lipid profile and liver function tests among the patients admitted to the Cardio-Coronary unit, General Hospital Kandy, Sri Lanka.

\section{METHOD}

\subsection{Study Setting}

The study was based on a case control design and the cases were recruited from consecutive admissions to the coronary care unit of the General Hospital Kandy with the diagnosis of myocardial infarction. Kandy district is situated in the hilly central region of Sri Lanka where climatic conditions and vegetation are different from those in the low-lying plains in the island. The Cardio Coronary Unit, at the General Hospital Kandy is a tertiary care unit and it provides coronary care services to the entire Kandy district.

\subsection{Recruitment of Cases and Controls}

The cases presented with a history of chest pain, subsequently confirmed as myocardial infarction based on ECG changes and positive cardiac biomarker "Troponin T". The Troponin-T test was performed using capillary blood as a bed side test using a standard kit (Roche CARDIAC Troponin T Sensitive ${ }^{\circledR}$ ) at the time of admission to the hospital and repeated 6 hours afterwards if the initial test was negative. The test was conducted according to the guide lines provided by the manufacturer. The positive Troponin $\mathrm{T}$ was considered essential along with ECG changes to confirm the diagnosis and recruitment. The patients who died immediately after the admission were excluded from the study. Controls were selected during the same period of time, among the patients who presented to the outpatient department of the same hospital with other ailments, unrelated to cardiovascular diseases. They were matched for age \pm 2 years and gender. Finally the study comprised 205 cases and 197 controls for the analysis.

\subsection{Assessment of Outcomes}

The study team trained two medical graduates for data collection. After obtaining consent from the selected patients, $5 \mathrm{ml}$ of venous blood were taken within 12 hours of admission to measure their lipid profile, liver enzymes, serum albumin and total bilirubin levels. The reliability of laboratory information was ensured by retesting ten percent of duplicated blood samples in another reputed laboratory.

Once the patient's general conditions were stable, details such as personal variables, information regarding known history of diabetes mellitus and hypertension, details on smoking habits, family history of ischaemic heart disease were collected using an interviewer-administered questionnaire. We defined a positive family history of IHD if a 1st degree male relative had IHD below 60 years of age or a female below 55 years of age. Anthropometric measurements were taken on third day, when patients were allowed to be in the standing position. Weight, height, waist circumference and hip circumference of each patient were measured by the trained interviewers using the metric units. Waist circumference was measured at the narrowest circumference between the costal margin and iliac crest. Hip circumference was taken at the maximum circumference over the buttocks. Blood pressure readings were taken from the records as they were measured regularly using the mercury sphygmomanometers.

\subsection{Statistical Method}

The data were initially entered into a Microsoft Excel work sheet and then analyzed using the statistical software package, SPSS version 17. Univariate analysis was performed with the data of a categorical nature to assess the associations between the occurrence of MI and independent variables. Logistic regression was used to find out the independent risk factors of MI.

Associations between the cases and controls with regard to their liver enzymes [serum aspartate transaminase (AST), alanine transaminase (ALT)], serum albumin, serum bilirubin levels were analyzed separately. For the purpose of categorization of these values, cutoff values given by the manufactures were used. Odds ratio and trends were calculated to assess the associations. Association between serum bilirubin levels among cases and controls were analyzed using bilirubin fifth.

\section{RESULTS}

The mean ages of cases and controls were 56 years (SD 
\pm 8.4 years) and 54 years ( $\mathrm{SD} \pm 9.8$ years) respectively. The case group comprised of 170 males and 35 females $(\mathrm{M}: \mathrm{F}$ ratio $=1: 0.21)$ and control group comprised 172 males and 42 females (M: $\mathrm{F}$ ratio $=1: 0.24$ ).

Table 1 shows comparison of risk factors elicited in the history between groups where all variables showed statistically significant odds ratios except the history of ex-smokers. Hypertension had the highest association with myocardial infarction with an odds ratio of 3.1. Family history of ischaemic heart disease had a weak association with MI when compared with the other variables. However, the anthropometric measurements (Body Mass Index-BMI and Waist-Hip Ratio-WHR) did not show an association with the occurrence of MI (Table 2).

Table 1. Univariate analysis of risk factors of myocardial infarction elicited in history and examination.

\begin{tabular}{|c|c|c|c|c|}
\hline Variables & & Cases & Controls & $\mathrm{OR}(\mathrm{CI})$ \\
\hline \multirow{2}{*}{ Family history } & Yes & 65 & 43 & \multirow{2}{*}{$1.66(1.06-2.60)$} \\
\hline & No & 140 & 154 & \\
\hline Total & & 205 & 197 & \\
\hline \multirow[b]{2}{*}{ Diabetes } & Yes & 78 & 37 & \multirow[b]{2}{*}{$2.68(1.70-4.72)$} \\
\hline & No & 126 & 160 & \\
\hline Total & & 204 & 197 & \multirow{3}{*}{$3.07(1.83-5.14)$} \\
\hline \multirow{2}{*}{ Hypertension } & Yes & 62 & 25 & \\
\hline & No & 139 & 172 & \\
\hline Total & & 201 & 197 & \\
\hline \multirow{3}{*}{ Smoking } & Current smoker & 87 & 37 & $2.60(1.6-4.3)$ \\
\hline & Ex-smoker & 36 & 66 & $0.61(0.37-1.0)$ \\
\hline & No & 81 & 90 & 1 \\
\hline Total & & 204 & 193 & \\
\hline
\end{tabular}

Table 2. Univariate analysis of anthropometric measurements as risk factors of MI.

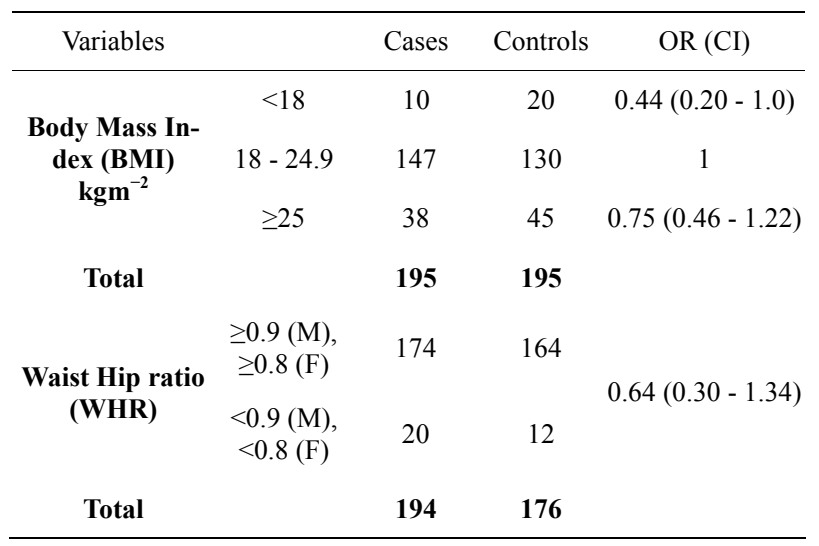

Of the variables studied under the lipid profile, total cholesterol levels $\geq 240 \mathrm{mg} / \mathrm{dl}$ and LDL-cholesterol (above $160 \mathrm{mg} / \mathrm{dl}$ ) showed statistically significant odds ratios $1.97(95 \% \mathrm{CI}, 1.22-3.21)$ and 3.01 (95\% CI, 1.68 - 5.39) respectively. However, other variables, triglycerides, HDL-cholesterol, Cholesterol to HDL ratio did not show an association with MI (Table 3). The final logistic regression model identified hypertension, diabetes, smoking and high LDL cholesterol levels as the independent risk factors of myocardial infarction (Table 4).

Of the liver enzymes, AST had the highest association with MI with an odds ratio of 13.8 (CI, $8.46-22.50$ ) whilst ALT also showed a significant association (OR-3. 30, CI, 2.18 - 4.99). Total bilirubin levels of 11 to 20 $\mathrm{mg} / \mathrm{dl}$ and $>21 \mathrm{mg} / \mathrm{dl}$ calculated a statistically significant odds ratios between cases and controls as 2.18 (CI 1.12 4.22) and 3. 82 (CI, 1.91 - 7.63) respectively (Table 5). Serum albumin did not have a statistically significant association.

Table 3. Univariate analysis of components of lipid profile as risk factors of MI.

\begin{tabular}{|c|c|c|c|c|}
\hline Variables & & Cases & Controls & OR (CI) \\
\hline \multirow{3}{*}{ Total cholesterol } & $\geq 240$ & 67 & 42 & $1.97(1.22-3.21)$ \\
\hline & $200-239$ & 53 & 52 & $1.26(0.78-2.04)$ \\
\hline & $<200$ & 83 & 103 & 1 \\
\hline \multirow[t]{2}{*}{ Total } & & 203 & 197 & \\
\hline & $\geq 200$ & 29 & 58 & $0.34(0.21-0.58)$ \\
\hline \multirow[t]{2}{*}{ Triglycerides } & $150-199$ & 28 & 37 & $0.53(0.30-0.92)$ \\
\hline & $<150$ & 146 & 102 & 1 \\
\hline \multirow[t]{2}{*}{ Total } & & 203 & 197 & \\
\hline & $\geq 160$ & 75 & 35 & $3.01(1.68-5.39)$ \\
\hline \multirow{3}{*}{ LDL } & $130-159$ & 47 & 48 & $1.38(0.77-2.46)$ \\
\hline & $100-129$ & 43 & 61 & $0.99(0.56-1.76)$ \\
\hline & $<100$ & 37 & 52 & 1 \\
\hline \multirow[t]{2}{*}{ Total } & & 202 & 196 & \\
\hline & $\begin{array}{l}\geq 40(\mathrm{M}) \\
\geq 50(\mathrm{~F})\end{array}$ & 37 & 31 & \\
\hline HDL & $\begin{array}{l}<40(\mathrm{M}) \\
<50(\mathrm{~F})\end{array}$ & 164 & 164 & $1.19(0.71-2.02)$ \\
\hline \multirow[t]{2}{*}{ Total } & & 201 & 195 & \\
\hline & $\geq 4.8$ & 65 & 43 & $1.67(0.99-2.84)$ \\
\hline \multirow[t]{2}{*}{ Cholesterol/HDL } & $3.8-4.7$ & 81 & 92 & $0.97(0.61-1.56)$ \\
\hline & $<3.8$ & 56 & 62 & 1 \\
\hline Total & & 202 & 197 & \\
\hline
\end{tabular}


Table 4. Independent risk factors of MI (Final conditional logistic regression model).

\begin{tabular}{cc}
\hline Variable & OR $(\mathrm{CI})$ \\
\hline Hypertension & $5.09(2.64-9.83)$ \\
Diabetes & $3.45(1.90-6.10)$ \\
Smoking & $1.95(1.44-2.65)$ \\
LDL cholesterol & $1.06(1.04-1.08)$ \\
\hline
\end{tabular}

Table 5. Association of liver enzyme, serum albumin and bilirubin levels and MI.

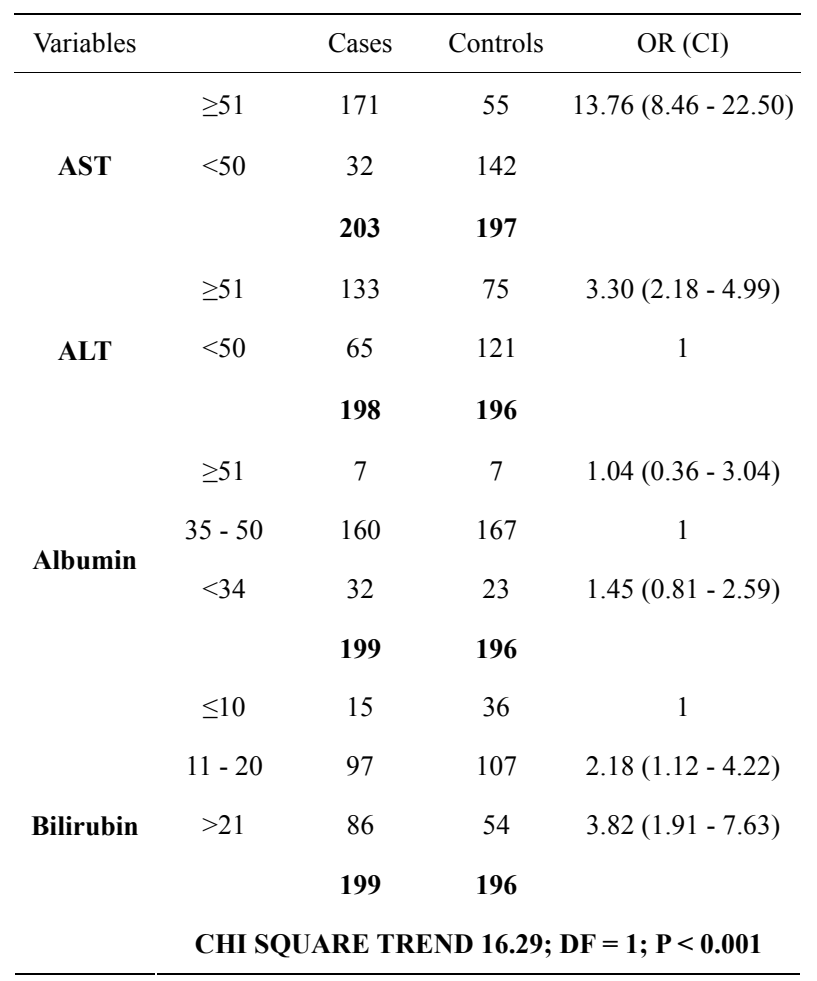

Results as shown in Table 6 demonstrate the increase in the association of MI along with the serum bilirubin levels.

\section{DISCUSSION}

The study found hypertension, diabetes, smoking and high LDL cholesterol levels as the important risk factors of myocardial infarction in the Kandy district, Sri Lanka. However, we did not find a significant association between the anthropometry (BMI and WHR) and myocardial infarction. We found significantly high levels of liver enzymes and bilirubin among cases compared with the control subjects.

In the global context, South Asians develop MI at younger ages compared with individuals from other countries which have been postulated to be due to beginning of exposure to major risk factors at young age [7].
Table 6. Bilirubin fifths and its association with MI.

\begin{tabular}{ccccc}
\hline Variables & & Cases & Controls & OR (CI) \\
\hline & $\leq 11.05$ & 27 & 52 & 1 \\
& $11.06-15.64$ & 32 & 49 & $1.26(0.66-2.39)$ \\
Total & $15.65-19.21$ & 44 & 32 & $2.65(1.38-5.08)$ \\
Bilirubin & $19.22-26.42$ & 47 & 31 & $2.92(1.53-5.59)$ \\
& $\geq 26.43$ & 46 & 32 & $2.77(1.45-5.29)$ \\
& Total & $\mathbf{1 9 6}$ & $\mathbf{1 9 6}$ & \\
\hline
\end{tabular}

A study done in Sri Lanka in 2005 has projected a $29 \%$ increase in hospitalization due to ischaemic heart disease in 2010 [8].

Among the risk factors of MI, diabetes has been identified as one of the important factors. A study done in UK had highlighted that the incidence of MI was not reduced even among the diabetic patients who were under strict glucose control [9]. This emphasized the importance of preventing people developing diabetes in the first instance rather than control.

It has been known to the scientific society that hypertension is one of the major risk factors of MI. The findings of Meta regression analysis using ordinal outcomes in 38 hypertension trials provided that lowering blood pressure reduced both the severity and frequency of fatal and recurrent attacks [10]. However, a study conducted using the data from the British Regional Heart Study (men) and British Women's Heart and Health Study (women) revealed that those with hypertension, irrespective of whether this was treated and controlled or not, were at greater risk of future cardiovascular disease than those who had normal blood pressure [11].

The world literature shows that the anthropometry is an important risk factor for MI. A study done in India, 1996, identified the waist hip ratio as a major risk factor of myocardial infarction [2]. However, our study did not confirm this association. This emphasizes that even within the Indian subcontinent, the risk factors of MI could be country specific.

Smoking is a known risk factor for MI worldwide. We found that the current smoking status had a significant association with MI but the ex-smokers had a significantly lower association with MI similar to the findings of previous reports $[2,12]$. This emphasizes the fact that cessation of smoking has a definitive beneficial effect on avoiding ischaemic heart disease.

This study showed dissimilarity to the published data in the analysis of lipid profile. The total cholesterol level, triglycerides and HDL, showed no association with MI, but high LDL level showed a significant association with MI. A case-control study published in India in 1996 revealed similar results, mentioning that lipid profile was 
not associated with MI [2].

Several past studies have shown a relationship between serum bilirubin levels and occurrence of MI. Therefore, we studied the association between serum bilirubin levels and MI further. The results revealed an S-shaped curve which was contrary to a previous research finding where it has shown a U-shaped association [13]. Of the liver enzymes, AST showed a clear association with MI, this could be a spurious finding as AST is also found in the myocardium and tends to elevate following MI. However, ALT, being specific to the liver and its high levels in the cases, needs explanation. As this study does not have baseline on ALT levels of cases before they developed MI, this association cannot be further evaluated.

We could not confirm the family history of MI as an independent risk factor, perhaps the familial nature of major risk factors, the diabetes and hypertension would have underestimated its effect. Benderly M., in 2010 showed the U-shape risk association with MI among lean and obese patients, however this study did not identify BMI or waist hip ratio as an important risk factor of MI [14].

In conclusion, we found that hypertension and diabetes are the major risk factors of ischemic heart disease. However, the anthropometric measurements did not show an association with myocardial infarction which could be unique to the central region of Sri Lanka.

\section{ACKNOWLEDGEMENT}

We thank the Japan International Corporation Agency for funding this research and Prof. S.N. Arseculeratne for his valuable comments.

\section{REFERENCES}

[1] WHO. Cardiovascular disease fact sheet number 317 , January 2011, viewed 30 March 2011. http://www.who.int/mediacentre/factsheets/fs317/en/inde x.html

[2] Pais, P., Pogue, J., Gerstein, H., Zachariah, E., Savitha, D., Jayprakash, S., Nayak, P.R. and Yusuf, S. (1996) Risk factors for acute myocardial infarction in Indians: A case-control study. Lancet, 348, 358-363. doi:10.1016/S0140-6736(96)02507-X

[3] Gupta, M., Doobay, A.V., Singh, N., Anand, S.S., Raja, F., Mawji, F., Kho, J., Karavetian, A., Yi, Q. and Yusuf, S. (2002) Risk factors, hospital management and outcomes after acute myocardial infarction in South Asian Canadians and matched control subjects. Canadian $\mathrm{Me}$ dical Association Journal (CMAJ), 166, 717-722.

[4] Teo, K.K., Liu, L., Chow, C.K., Wang, X., Islam, S., Jiang, L., Sanderson, J.E., Rangarajan, S. and Yusuf, S.
(2009) Potentially modifiable risk factors associated with myocardial infarction in China: The interheart China study. Heart, 95, 1857-1864. doi:10.1136/hrt.2008.155796

[5] Olusi, S.O., Prabha, K. and Sugathan, T.N. (1999) Biochemical risk factors for myocardial infarction among South Asian immigrants and Arabs. Annals of Saudi Medicine, 19, 147-149.

[6] Wijewardene, K., Mohideen, M.R., Mendis, S., Fernando, D.S., Kulathilaka, T., Weerasekara, D. and Uluwitta, P. (2005) Prevalence of hypertension, diabetes and obesity: Baseline findings of a population based survey in four provinces in Sri Lanka. Ceylon Medical Journal, 50, $62-$ 70.

[7] Joshi, P., Islam, S., Pais, P., Reddy, S., Dorairaj, P., Kazmi, K., Pandey, M.R., Haque, S., Mendis, S., Rangarajan, S. and Yusuf, S. (2007) Risk factors for early myocardial infarction in south Asians compared with individuals in other countries. JAMA: The Journal of the American Medical Association, 297, 286-294. doi:10.1001/jama.297.3.286

[8] Premaratne, R., Amarasinghe, A. and Wickremasinghe, A.R. (2005) Hospitalisation trends due to selected noncommunicable diseases in Sri Lanka, 2005-2010. Ceylon Medical Journal, 50, 51-54

[9] Macisaac, R.J. and Jerums, G. (2011) Intensive glucose control and cardiovascular outcomes in type 2 diabetes (31 April 2010). Heart Lung Circulation, 20, 647-654.

[10] Geeganage, C.M., Tracy, M., Bath, M.W. and Bath, P.M. (2010) Blood pressure reduction and cardiovascular prevention: Meta-regression using ordered categorical (ordinal) event data. Journal of Hypertension, 28, 19951999. doi:10.1097/HJH.0b013e32833c7a32

[11] Lawlor, D.A., Kim, L., Morris, R., Amuzu, A., Whincup, P. and Ebrahim, S. (2011) Survival with treated and wellcontrolled blood pressure: Findings from a prospective cohort study. PLoS One, 6, e17792

[12] Björck, L., Rosengren, A., Wallentin, L. and Stenestrand, U. (2009) Smoking in relation to ST-segment elevation acute myocardial infarction: Findings from the register of information and knowledge about Swedish heart intensive care admissions. Heart, 95, 1006-1011. doi:10.1136/hrt.2008.153064

[13] Troughton, J.A., Woodside, J.V., Young, I.S., Arveiler, D., Amouyel, P., Ferrieres, J., Ducimetiere, P., Petterson, C.C., Kee, F., Yarnell, J.W. and Evans, A. (2007) Bilirubin and coronary heart disease risk in the prospective epidemiological study of myocardial infarction (PRIME). European Journal of Cardiovascular Prevention and Rehabilitation, 14, 79-84. doi:10.1097/01.hjr.0000230097.81202.9f

[14] Benderly, M., Boyko, V. and Gildbourt, U. (2010) Relation of body mass index to mortality among men with coronary heart disease. The American Journal of Cardiology, 106, 297-304. doi:10.1016/j.amjcard.2010.03.078 